\title{
Processo saúde-doença: um estudo das representaçóes sociais de trabalhadores com DORT
}

\author{
I ${ }^{1}$ Vanusa Caiafa Caetano, ${ }^{2}$ Danielle Teles Cruz, ${ }^{3}$ Girlene Alves Silva, \\ ${ }^{4}$ Isabel Cristina Gonçalves Leite, ${ }^{5}$ Simone Meira Carvalho I
}

Resumo: O artigo origina-se de pesquisa que analisou as representaçóes sociais do processo saúde-doença entre trabalhadores portadores de distúrbios osteomusculares relacionados ao trabalho (DORT), usuários do Centro de Referência em Saúde do Trabalhador (CEREST) de Juiz de Fora, MG. O recurso de apreensão das informações foram entrevistas semiestruturadas, realizadas junto a 12 trabalhadoras com idade entre 29 e 55 anos. As informações foram submetidas a análise temática. A partir dos temas de análise, chamados "representação da saúde" e "representação da doença", para essas trabalhadoras, o adoecimento e a incapacidade laboral representam uma lacuna dolorosa e a destruição dos projetos de vida. Os quadros de deterioração das condições de vida e degradação do trabalho, refletidos sobre a saúde das trabalhadoras, nos levam a sustentar que a prevenção dos problemas de saúde que encontraria maior grau de resolução seria o replanejamento da organização do processo de trabalho e da efetiva atuação das políticas públicas de saúde, através de representações simbólicas mais amplas sobre saúde, doença e cura.

> Palavras-chave: saúde; doença; trabalhador; DORT; representação social.

\author{
1 Professora adjunta da \\ Faculdade de Fisioterapia da \\ UFJF. Endereço eletrônico: \\ vanusa.caiafa@ufjf.edu.br \\ ${ }_{2}$ Professora auxiliar da \\ Faculdade de Fisioterapia da \\ UFJF. Endereço eletrônico: \\ danitcruz@yahoo.com.br \\ ${ }^{3}$ Professora adjunta da \\ Faculdade de Enfermagem \\ da UFJF. Endereço eletrônico: \\ girleneas@terra.com.br \\ ${ }^{4}$ Professora adjunta da \\ Faculdade de Medicina da UFJF. \\ Endereço eletrônico: isabel. \\ leite@ufjf.edu.br \\ ${ }^{5}$ Professora assistente da \\ Faculdade de Fisioterapia da \\ UFJF. Endereço eletrônico: \\ simeiracarvalho@hotmail.com
}

Recebido em: 05/09/2011. Aprovado em: 21/06/2012. 
A reestruturação do processo produtivo verificada nas últimas décadas implicou alterações diretas na saúde do trabalhador, modificando o perfil de adoecimento e sofrimento desses indivíduos. Dependendo da forma de organização do processo de trabalho, o cotidiano no ambiente laboral é configurado por contextos nos quais os modos de se trabalhar, de lidar com o tempo e equipamentos são seguramente danosos à saúde (SATO, 2002). Dentro desse contexto, observase um aumento significativo dos distúrbios osteomusculares relacionados ao trabalho (DORT), que se configuram atualmente como importante problema de saúde pública (HOEFEL et al., 2004; WALSH et al., 2004). A incapacidade e a sintomatologia, bem como o sofrimento dos portadores de DORT, apresentam causas e consequências socialmente engendradas que não devem ser desconsideradas (WALSH et al., 2004).

Caracterizados pela dor forte, os DORT costumam contrastar com lesōes relativamente benignas e com poucos sinais objetivos, sendo este um paradoxo de confusão entre profissionais envolvidos com a saúde ocupacional, pela invisibilidade orgânica desta patologia (WALSH et al., 2004). Além de contribuir para a deterioração das relações laborais e sociais, consequentemente, a baixa expectativa quanto à capacidade futura para o trabalho também é observada (BRASIL, 2006). Na opinião de Wünsch Filho (2004), a adoção de uma política em saúde do trabalhador que possa nortear as ações dos diferentes níveis governamentais deverá ter influência substancial para o desenvolvimento da sociedade, melhorando a qualidade de vida das pessoas.

No contexto das contradições postas pelo mundo do trabalho no qual o processo de adoecimento está dentro de toda essa cadeia do processo produtivo, buscando valorizar os elementos das representações dos trabalhadores em processo de adoecimento, esta pesquisa teve como objetivo analisar as representações sociais do processo saúde-doença entre trabalhadores com DORT usuários do Sistema Único de Saúde (SUS), inseridos no Programa de Reabilitação Física do Centro de Referência em Saúde do Trabalhador (CEREST), através do Departamento de Saúde do Trabalhador (DSAT), do município de Juiz de Fora, MG.

De acordo com os registros consultados do CEREST/DSAT, encontramos 1.800 trabalhadores cadastrados no Programa de Reabilitação Física, entre acidentes de trabalho e doenças relacionadas ao trabalho. Porém o número de 
trabalhadores atualmente frequentes é em média 300 por mês, calculado a partir

dos dados encontrados no período de 12 meses. A maioria deles se encontra em afastamento ou desempregados, tendo sua doença comunicada ao INSS, através da Comunicação de Acidente de Trabalho (CAT).

\section{Ancoragem teórica e metodológica do estudo}

O presente estudo foi desenvolvido numa abordagem qualitativa, que busca conhecer e trabalhar aspectos particulares do universo dos significados, valores e atitudes que compreendem o espaço das relaçôes e fenômenos dos sujeitos (MINAYO, 2004). Desse modo, pensar o processo de adoecimento do trabalhador nos remete a valorizar esses sujeitos tomando em consideração a experiência e a vivência não somente como trabalhador, mas também suas representações sobre processo de saúde-adoecimento. Assim, tomamos como abordagem teórica a Teoria das Representações Sociais.

A Teoria das Representações Sociais nos ajuda a compreender o universo que abarca a saúde do trabalhador e as representações dos trabalhadores com DORT, configurando-se como elo entre as interfaces do processo saúde-adoecimento. Esta teoria possibilita a integração de aspectos implícitos e explícitos do comportamento dos indivíduos, resultantes da interação social, o que nos leva ao entendimento da realidade e dos fenômenos humanos a partir de uma perspectiva coletiva, sem perder o olhar da individualidade (CAETANO; CRUZ; LEITE, 2009; SILVA et al., 2007; JODELET, 2001).

De acordo com Moscovici (1978), a ideia de representação vai além da noção de atitude, imagem e opinião, destacando a diferença existente entre elas. Para o autor, não existem nas representações sociais rupturas entre o universo externo e o interno ao indivíduo ou grupo. Isso nos remete ao fato de que sujeito e objeto não são distintos; em um contexto ativo, o objeto da representação vai sendo construído pela pessoa ou coletividade. Portanto, a representação toma como base as relações existentes entre a memória e a capacidade de continuar a imaginar, o que a torna um processo dinâmico e em movimento.

Herzlich (1972), ao se referir ao papel das representações na vida dos indivíduos, alerta-nos para o fato de ser a representação um dos instrumentos pelos quais o indivíduo ou o grupo apreende seu ambiente. É um dos níveis em que as estruturas sociais lhe são acessíveis e elas exercem papel fundamental 
na formação da comunicação e das condutas sociais. Na mesma perspectiva, Wagner (1998, p. 10) diz que "as representações significam mais do que uma imagem estática de um objeto na mente das pessoas; elas compreendem também seu comportamento e a prática interativa de um grupo".

Se as representações sociais exercem papel fundamental na dinâmica das relações sociais e práticas, é porque respondem às seguintes funçôes: funções de saber que permitem compreender e explicar a realidade, funções identitárias que definem a identidade e permitem proteger a especificidade do grupo, funções de orientação que guiam os comportamentos e as práticas e, finalmente, as funções justificadoras, visto que permitem a posteriori a justificativa das tomadas de posição e comportamentos (ABRIC, 1998). Portanto, para Jodelet (2001, p. 22), representação social é uma "forma de conhecimento, socialmente elaborado e partilhado, tendo uma visão prática e concorrendo para a construção de uma realidade comum a um conjunto social”.

Enfatizamos que a elaboração e o funcionamento de uma representação podem ser entendidos pelos processos de objetivação e ancoragem que compreendem a articulação entre o conteúdo cognitivo e as determinações sócio-históricas em que surgem e circulam as representações. É no processo de ancoragem que consiste a associação cognitiva do objeto - podendo ser este ideias, relações, acontecimentos, doenças - a um sistema preexistente de pensamento social e nas transformações da realidade sobre a qual intervêm. Isto é, ancorar é transformar o novo, o não familiar em familiar, para uma aceitação do desconhecido através de um processo de classificação estruturante que dá forma específica ao conhecimento sobre o objeto, tornando-o concreto (JODELET, 2001).

Desse modo, é no processo de elaborar e reelaborar representações sobre o processo de sentir-se saudável ou se perceber doente que nos subsidiamos desse referencial para compreender esse universo de tomada de atitude direcionada ao objeto socialmente significante que é o processo saúde-doença.

\section{O local do encontro}

O local onde aconteceram os encontros com os trabalhadores foi o Centro de Referência em Saúde do Trabalhador ${ }^{1}$ (CEREST), localizado no município de Juiz de Fora, estado de Minas Gerais, que atende à Macrorregião de Saúde que congrega 37 municípios da Zona da Mata Mineira. 


\section{Os sujeitos e a apreensão das informações}

Realizamos a coleta de dados por meio de entrevistas semiestruturadas, de forma individual, registradas em microgravador. Os entrevistados foram escolhidos a partir dos dados de caracterização que compóem a primeira fase da pesquisa que teve como critério de inclusão estarem inseridos no Programa de Reabilitação Física do CEREST desde o ano de 2006 e com nexo ocupacional de DORT. Assim, o convite foi feito para todos os trabalhadores de ambos os sexos que preenchiam o critério acima referido. No entanto, no estudo, como o acesso às trabalhadoras desde o início da pesquisa foi mais fácil, pela própria natureza de as mesmas seguirem as recomendaçôes terapêuticas e serem mais acometidas pelos DORT, constitui-se, portanto, um grupo de sujeitos composto pelas trabalhadoras.

Foram entrevistadas 12 trabalhadoras. A idade variou entre 29 e 55 anos, caracterizadas de maneira que o anonimato permanecesse preservado, identificadas por suas inicias. Elas são oriundas de categorias profissionais similares sobre o ponto de vista social, com baixa qualificação e remuneração. Dentre as funções identificadas, encontramos: três costureiras, duas em serviços gerais, duas domésticas, faxineira, auxiliar de fisioterapia, operadora de caixa, enroladeira de papel higiênico e secretária de digitação. Verificamos que as trabalhadoras iniciaram suas vidas profissionais precocemente, sendo a idade mínima descrita de seis anos e a máxima de 14 anos, ambas consideradas como trabalho infantil.

Segundo Turato (2003) e Minayo (2004), a amostragem deve ser intencionada pela busca proposital de indivíduos que vivenciam o problema em foco e/ou têm conhecimento sobre ele. $\mathrm{O}$ número de entrevistas se encerrou quando as informaçôes alcançadas foram consideradas suficientes e atingiram a reincidência das informaçôes.

A entrada do pesquisador no campo se deu tomando a relação que a Universidade Federal de Juiz de Fora (UFJF) e O CEREST desenvolvem estudos no campo da pesquisa e capacitação na saúde do trabalhador. Desse modo, a escolha desse cenário facilitou o acesso aos sujeitos desse estudo. Na ocasião do primeiro contato com os trabalhadores, quando a pesquisadora se apresentava, era de acordo com o interesse deles e a disponibilidade agendada com a data e o horário da entrevista. 


\section{Os aspectos éticos da pesquisa}

As trabalhadoras receberam informações sobre a pesquisa e, após concordarem em participar, assinaram um termo de consentimento livre e esclarecido (TCLE). Ressalta-se que a pesquisa foi aprovada pelo Comitê de Ética e Pesquisa (CEP) da Universidade Federal de Juiz de Fora (UFJF), sob o parecer n 326/2007. Nessa ocasião, eram reafirmados os compromissos com o anonimato das trabalhadoras participantes.

\section{A organização dos achados}

Seguimos como referência as três etapas cronológicas sugeridas por Bardin(1977), para a organização da análise: pré-análise, descrição analítica e interpretação inferencial. Uma vez categorizadas as falas das entrevistadas mediante os objetivos propostos, foram feitas as inferências necessárias com base na literatura científica, visando alcançar o objetivo pretendido no presente estudo.

Os resultados da análise das representações sociais da saúde e doença entre trabalhadoras com DORT serão apresentados em dois momentos: no primeiro, analisaremos as representações da saúde e, no segundo, as representaçôes da doença.

\section{Resultados e discussão dos achados}

Seguindo as proposições para a análise e interpretação dos dados, as unidades temáticas abaixo descritas serão apresentadas de forma a expressar o conteúdo presente nas representações sociais das trabalhadoras envolvidas no estudo.

\section{A representação da saúde}

A representação elaborada para a saúde nos remeteu aos significados reducionistas que a explicavam, como ausência de doença, segundo depoimentos a seguir:

Ah! Eu acho que saúde é quem não tem uma doença, assim que... Quem não tem saúde é aquele que tem uma doença, que é como câncer... Eu tenho saúde, sim! (EANL)

Saúde é não ter dor nenhuma, é não ter nada... Aquelas dorzinhas, dor de cabeça, que dá e passa... Agora uma dorzinha que fica assim perturbando, é muito ruim... (AIAO)

Observamos, na análise, que essas representaçōes nos apresentam a condição de saúde como ausência de sinais e sintomas indicadores de algum agravo à saúde, ou até mesmo a presença instalada de doença. A concepção apresentada pelas 
mulheres no que diz respeito à saúde parece não considerar o indivíduo como

um ser integral inserido em um contexto ambiental, social, econômico e político. Portanto, vulnerável as questões ligadas dentro desses contextos.

Segundo Minayo e Thedim (1997), os trabalhadores, de uma maneira geral, associam a saúde com a capacidade de poder trabalhar e a doença com a incapacidade. Eles vivenciam o corpo como uma fonte de subsistência, de reprodução e de aquisição de bens. A saúde assim entendida, e a doença por sua oposição, constituem valores fundamentais de suas vidas, segundo os depoimentos a seguir, dentro de uma visão mais ampliada:

Saúde é tudo, sem saúde a gente não faz nada, a gente é um zero à esquerda. Ué... saúde é tudo, é essencial na vida da gente. Sem saúde não vai a lugar nenhum. (DRL)

E... porque quando a pessoa é saudável, a pessoa não toma remédio, para mim eu acho isso. Então quem é dependente do remédio... Eu não me acho uma pessoa saudável. Então... o problema de saúde é tudo. (MJBS)

O entendimento da saúde como ausência de doença e como saúde do corpo parece estar relacionado aos fenômenos identificados na sociedade como crise informacional e institucional, evidenciando que a saúde ainda é entendida de forma imediatista, o que pode indicar a dificuldade de comportamentos preventivos por parte dos trabalhadores (LEFF, 2001).

A doença no trabalho, enquanto fenômeno particular e social, que revela ou oculta o conteúdo das mediações que a originam, não deve ser tratada como uma unidade analítica simples, dissociada de seus eixos mediadores. Deve ser considerado todo o contexto social, econômico, psíquico, estabelecendo uma nova interpretação para que ações preventivas sejam alcançadas (CAETANO; CRUZ; LEITE, 2009).

Se em um dado momento as trabalhadoras trazem representações sobre a saúde ancoradas na condição de ausência de doenças, elas também, ao vivenciarem novas experiências, compartilharem novos saberes e pela necessidade de fazer a gestão cotidiana do seguimento da DORT em suas vidas, elaboram suas representações sobre a saúde para além do conceito de saúde como ausência de doença, ao grau de superação do adoecimento, de superação da dor e da incapacidade. Desse modo, ao buscarem um sentido para a vida, e rechaçando o rótulo da inutilidade, elas comparam doenças mais graves como forma de sobrepujar sua situação, conforme recortes das falas: 
Ah, porque, sei lá, porque eu não sou inválida igual o pessoal olha para mim, e me vê como uma inválida, eu não acho que eu não sou assim... Eu ainda tenho alguma utilidade... Eu não me sinto incapaz totalmente... (DRL)

E assim convivendo com muita dor, mas não posso reclamar, porque eu já melhorei bastante... Saúde, boa não, mas eu tento passar por cima, porque se eu for parar para valorizar minha saúde um pouco assim das coisas, não vou viver, porque é tanta coisa... Aí... se eu queixar assim... Pressão alta eu não tenho, não tenho diabete, não tenho nada disso. (JSA)

Isso perto de muitos problemas na vida, ele não é nada... não é um problema grave que eu tenho não, mas a gente tem uma não sei... Eu sou uma pessoa que eu não, eu não tenho que ficar reclamando, porque tem coisas, situação na vida muito pior com certeza... (EANL)

O conceito de saúde vem se transformando ao longo das últimas décadas, sobretudo quando se articula com propostas de modelos de atenção à saúde adotados. Ao passarmos de um modelo hospitalocêntrico para um modelo assistencial promotor da saúde, preventivo, pela participação popular e a interdisciplinaridade dos diferentes profissionais da saúde, é esperado que os sujeitos elaborem novas representações sobre o entendimento do que venha a ser saúde. Nesta nova ordem, por vezes é percebido que o sentido dado à saúde já não é como o avesso da doença, mas como a busca do equilíbrio do ser humano, devendo, portanto, romper os estreitos limites da assistência curativa (CHAMMÉ, 1988).

A representação da saúde abarca fatores que condicionam e determinam a vida do sujeito, garantindo uma vida livre de dor, em um corpo organicamente equilibrado, segundo os relatos a seguir:

É você ter uma vida saudável... caminhar. É alimentação boa. Praticar esporte, que não é o meu caso, que eu não faço, né? Nem caminhar ultimamente eu tenho caminhado mais. Não beber, não fumar, procurar dormir mais cedo... (EIPM)

É você ter o que comer, é andar bem alimentado e não depender do SUS... para mim, tudo isso aí é saúde. Eu não me considero saudável, para eu ser saudável eu não tinha que ter nada disso. (LMBM)

Esta concepção pode estar relacionada com a constatação de que as políticas públicas como um todo se encontram cada vez menos eficientes, não proporcionando um atendimento efetivo à população. Tais práticas assistenciais encontram-se fragmentadas e desarticuladas com os princípios e diretrizes que norteiam o SUS, contrapondo-se às políticas de promoção da saúde e humanização, violando o direto à saúde (BAHIA; SCHEFFER, 2010). 
Não obstante, todo o cuidado com o corpo não poderá eximir o adoecimento, cujos fatores causais podem ser múltiplos nos ambientes laborais, relativos ao processo de organização do trabalho. Para essas trabalhadoras, o adoecimento e a incapacidade laboral representam uma lacuna dolorosa e a destruição dos projetos de vida.

\section{A representação da doença}

Nesta categoria, apresentamos a discussão sobre as representações das trabalhadoras acerca da doença DORT, que é capaz de trazer limitações e incapacidades que repercutem tanto no desenvolvimento de atividades de vida diária quanto no da própria vida social, comprometidas pela dor e perda de movimento, bem como pela sensação de dependência. Os recortes dos depoimentos ilustram essas representaçôes:

Nunca dependi de ninguém para fazer nada para mim... Agora dependo dos outros pra quase tudo... Interfere em quase tudo! Para você ter uma ideia não posso jogar um baralho... Eu não consigo empurrar o carrinho, eu começo a passar mal... (DRL).

Diária, lavar, por exemplo, assim... ariar uma panela... eu não tenho firmeza para ariar uma panela, esfregar uma roupa... Você se sente uma pessoa assim inútil... Às vezes entendeu... Aí você começa a juntar... a idade, o tempo, aqui fora, o desemprego, como que está entendeu... Como você vai arrumar um emprego, uma carteira sua que está carimbada lá... (EANL).

Se eu tiver que fazer uma dieta eu não posso por causa dos medicamentos. Caminhar... não posso, porque esses problemas... ele te prende de uma maneira ou outra... Você fica presa, é tipo uma prisão, uma cadeia aberta, porque você não pode ter uma vida normal igual a todo mundo tem... eu acredito que... eu não volto mais o que eu era antes... De tarde eu falava... "Fulana" a minha patinha está quebrada, porque eu não aguentava nem balançar. (EIPM).

As falas das trabalhadoras configuram em adoecimento sobre as quais tiveram suas vidas alteradas em função do trabalho. Isso implica a necessidade de se reconhecer como o trabalho modifica o trabalhador, ressaltando a importância das açôes dos serviços de saúde ocupacional destinadas a avaliar as situações de risco ou de alterações de saúde no trabalho (ROCHA; FELLI, 2004).

Outro agravante é a situação econômica, dificultada ainda mais em função do afastamento do trabalho. As entrevistadas do presente estudo demonstram essas características, muitas vezes pelo medo de perderem o emprego e de não terem como arcar com as despesas familiares e pessoais. Nesse contexto, elas realizavam 
as tarefas laborais, ainda que com dor, podendo piorar o quadro em função da necessidade de manter a renda familiar, conforme os discursos configurados abaixo:

E chegou um tempo que eu não estava tendo assim rendimento no trabalho. Aí, dei continuidade, continuei trabalhando mesmo com dor... Eu ficava assim... se eu falar, vou perder um emprego, onde é que eu vou arrumar um serviço? ... Eu já estava assim com uns 40 anos, onde é que eu vou arrumar um serviço com tanta menina nova no mercado... disputando. (EANL).

Eu trabalhava umas 12 horas... E hora que fosse fazer um exame, ia dar que eu estava com problema e não ia poder trabalhar, endividada e sem dinheiro para pagar minhas dívidas... Eu enrolava papel higiênico, tinha produção de 3000 rolos por dia... Quem não desse produção ia ser demitido, eu logo fiquei assim,fiquei com medo deles me demitirem, eu precisando trabalhar para limpar meu nome. Aí eu conseguia dar a produção. (AIAO)

Eu acho que o problema da costura, nessas fábricas, a minha produção era alta demais, você entendeu... Então quanto mais eu produzisse, mais eu ganhava, o salário aumentava, você entendeu?... Aí para mim compensava, eu dava tudo de mim... (EIPM)

Para Neves e Nunes (2010), alguns significados inerentes ao mundo do trabalho são vivenciados pelos trabalhadores, como a dor que precisa ser "calada", o sofrer contido, refletindo a necessidade de a pessoa manter-se sempre apta para o trabalho, íntegra na sua totalidade e produtiva aos olhos das exigências do trabalho. Ou seja, calar a dor seria mimetizar um "tipo ideal" de trabalhador, adequado a este sistema capitalista de produção. Entretanto, essas trabalhadoras sabem o que as fez adoecer, são capazes de identificar os riscos presentes nos ambientes de trabalho, tais como a pressão temporal, os movimentos repetitivos, o aumento da produção, a competitividade, dentre outros, conforme os depoimentos:

Excesso de serviço e pressão... O tempo era curto e muito serviço. Era serviço pesado, posição errada... Eu tinha que contar as cuecas, separar as cores, mandar para máquina, fazer molde, tudo vinha em cima de mim. Eu cada vez piorando... pegando aqueles rolos com 19 quilos, num lugar apertado, caixa caindo em cima de mim, caixa de 26,30 quilos... (DRL).

Trabalhei à noite, no turno da noite, trabalhei durante o dia... Mas era só produção... Carretas e mais carretas chegando... Às vezes não tinha lá as coisas pra fazer papel higiênico, eles botavam lá para encher carretas, aqueles fardos enormes, para encher uma carreta enorme. (AIAO).

Trabalhando! Overloque... tinha que cortar e ficava o dia inteiro assim. Passava e cortava, aí os dedos ficaram duros... meu olho partia, não conseguia olhar pro chão. Me sinto podre... mais podre, braço podre, tudo podre.Isso só a gente que tem é que sabe. (AMS). 
Este modelo capitalista que visa à produção em detrimento das condições de saúde do trabalhador é capaz de transformar o sentimento de um indivíduo produtivo em algo que não serve mais, inútil e que pode ser descartado. $\mathrm{Na}$ opinião de Lacaz (2007), a relação entre trabalho e saúde-doença parte da ideia cartesiana do corpo como máquina, o qual se expõe a fatores de risco. Dessa maneira, as consequências do trabalho para a saúde são resultantes da interação corpo (hospedeiro) com fatores (físicos, biológicos, químicos, mecânicos) existentes no ambiente de trabalho. Assim, os "limites de tolerância" e "limites biológicos de exposição" distinguem a intervenção na realidade laboral, no sentido de adaptar o ambiente e as condições de trabalho dentro de parâmetros preconizados para a média de trabalhadores normais quanto à suscetibilidade individual aos fatores de risco.

Estas trabalhadoras são, frequentemente, expostas à discriminação no trabalho, na família, na sociedade, nos serviços de saúde e perícias médicas. Tais circunstâncias impõem às mesmas um sofrimento intenso, agregando sentimentos de invalidez, humilhação e preconceito, seguido da invisibilidade orgânica dessas patologias, restando-lhes apenas a sintomatologia subjetiva existente perante a dor. Alguns depoimentos configuram esta situação:

Eu me sentia o resto do ser humano, a coisa mais triste, as últimas das pessoas... Sabe quando você está passando mal e a pessoa fala... Fulana, suas mãos não estão inchadas, é porque você está muito gorda... Será que você não está vendo que isso aqui é inchaço... Aqui, olhe minhas mãos. (LMBM).

Eu tenho medo quando a gente dá o vale transporte, o trocador olha para sua cara e olha pro vale, e olha pro braço. Um afasta de você para não te esbarrar sabe, muito chato, humilhante... é muita discriminação... A gente sofre muito preconceito, demais. (MAS).

É tudo [choro] é ônibus... Que seja alguma coisa que tenha que assinar, eu custo para conseguir pegar e prender o papel... Eu me sinto constrangida, porque o pessoal não sabe, e é um mínimo que eu não consigo, aí eu fico chateada... [choro]. ... só que eu sinto que eu poderia fazer mais, e não dá... (JSA).

Os quadros de deterioração das condições de vida e degradação do trabalho e seus reflexos sobre a saúde das entrevistadas nos levam a sugerir que, para a realidade local estudada, a prevenção dos problemas de saúde que encontraria maior grau de resolução seria o replanejamento da organização do processo de trabalho e da efetiva atuação das políticas públicas de saúde articulada com outros setores que atuam nesse campo, tornando o serviço mais efetivo. Assim, a 
busca de instrumentos que privilegiem medidas de prevenção deve ser ampliada, incorporando o conhecimento dos trabalhadores para que melhorias nas condições de trabalho e defesa da saúde possam ser potencializadas (LACAZ, 2007).

Dentre outras repercussões, localizamos representações da doença que encontram o desgaste físico e emocional consequente da busca constante de tratamentos e do descrédito comumente vivenciado pelos sentimentos de impotência, frustração e falta de expectativas futuras associadas à perda da capacidade laboral e a questionamentos da identidade e da própria vida, em sua razão de ser.

Então assim, realmente muda a vida da gente toda e muito. Ah... representa assim... insatisfação, né? Muito grande e... é como se a gente fosse assim... Como é que eu vou falar... é como se a gente fosse inútil... Então, assim, é muita frustração, insatisfação, a gente poder... Você poder fazer tudo, não sentir dor. (SMSR).

Aí eu estava sem remédio, eu não estava saindo de casa, porque eu fico assim, ó... [tremendo], com medo, eu não faço nada... eu não aguento de dor... Do jeito que está, está muito ruim [choro], eu não estou vivendo, estou vegetando, porque isso para mim não é vida, ficar dentro de casa trancada sem fazer nada... (ARR).

Aí eu paro de comer, não consigo comer... só água, só coisa que me desce reto, que eu não consigo mastigar, porque se eu mastigar eu mastigo a língua... Eu não consigo comer de jeito nenhum. Eu não era assim... eu era normal. E esse braço fica morto... fica morto, dormente. Agora eu não faço mais nada... (MAS)

Pior para mim é ficar do jeito que eu estou sabe... dói muito, eu ando com remédio na bolsa para tirar a dor. Eu me sinto péssima (voz trêmula), tem hora que dá vontade de juntar tudo e sumir no mundo... Estou vivendo no escuro... Olha quanta coisa já acarretou desde o tempo que eu parei por causa desse ombro pra cá. Olha como é minha saúde... (LAS).

Para Laplantine (1991), o normal e o patológico são pensados em termos de harmonia e desarmonia, equilíbrio e desequilíbrio, e a doença considerada como um desarranjo, por excesso ou falta. Dessa forma, qualquer que seja a diversidade dos sistemas de representações advindas deste modelo, a uma compreensão danosa se opõe uma compreensão funcional. Cada indivíduo é caracterizado pela particularidade única de um equilíbrio e predisposição a determinado desequilíbrio, razão pela qual cada um estará sujeito a sua própria doença.

A experiência da doença é então vivenciada de maneira que podemos destacar o conceito da língua inglesa para doença sobre a qual Laplantine (1991) nos chama atenção. A língua inglesa possui tripla terminologia: "disease (a doença tal como ela é apreendida pelo conhecimento médico), illness (a doença como 
é experimentada pelo doente) e sickness (um estado muito menos grave e mais incerto que o precedente; em geral o mal-estar)" (LAPLANTINE, 1991, p. 15). $\mathrm{O}$ autor também destaca que o vocábulo illness pode ser entendido como dois pontos de vista: doença-sujeito e doença-sociedade, o que reflete a experiência subjetiva do doente e comportamentos sócio-culturais ligados à doença.

Baseada nesta perspectiva teórico-metodológica, a compreensão do adoecer deve ser entendida como recortes de uma realidade vivida do ser doente, para que políticas e ações que contemplem os trabalhadores sejam efetivamente aplicadas (GOMES; MENDONÇA; PONTES, 2002). Independentemente do modelo teórico adotado pelo profissional, torna-se necessário ampliar a compreensão do processo de saúde e a conscientização de que o corpo biológico é desenvolvido dentro de um ambiente cultural e social distintos entre os pares. Dessa forma, os sentimentos, as experiências e a história de cada um são fatores que devem ser considerados nas inúmeras estratégias de intervenção (AUGUSTO et al., 2008).

\section{Considerações finais}

Os resultados do presente estudo nos mostraram que as mulheres trabalhadoras representam a saúde como valores fundamentais de suas vidas, assim como a ausência de doença. Não obstante, a doença foi representada pela incapacidade e limitações que repercutem no desenvolvimento das atividades de vida diária e da vida social, comprometidas pela dor, agravadas pela perda dos movimentos, vivenciadas pelos sentimentos de impotência e degradação das condições de vida e trabalho.

Configurados como síndromes complexas, vistos de maneira fragmentada dentro de uma concepção mecanicista do organismo humano e caracterizados por seus sintomas subjetivos e pela ausência de sinais clínicos objetivos, os DORT representam, na íntegra, do ponto de vista da saúde pública, um grave problema que demanda atenção e medidas de caráter emergencial.

Tais questôes podem estar relacionadas pela constatação de que as políticas públicas como um todo ainda são pouco eficientes, pois não proporcionam atendimento efetivo à população. Essas práticas assistenciais precisam ser pensadas de maneira articulada com os princípios e diretrizes que norteiam o SUS - pensar e fazer uma prática de saúde dentro dessa perspectiva e buscar superar a violação do direto à saúde. Dessa forma, sustenta-se uma clara defesa 
em considerarmos a necessidade da prevenção dos problemas de saúde através de uma atenção humanizada, integral e equânime com responsabilização, vínculo e, sobretudo, o replanejamento dos processos de organização do trabalho.

Esta pesquisa não pretende esgotar o assunto, mas sugere que estudos posteriores continuem examinando continuamente a representação que os trabalhadores com DORT elaboram sobre o processo de adoecer, bem como focalizar também a participação dos profissionais de saúde nas estratégias de reduzir a vulnerabilidade ao adoecimento e às incapacidades. Acrescenta-se o fato de não deixar de valorizar o papel das instituiçôes como cenário não só gerador de adoecimento, mas como responsável em propor ambiente de trabalho saudável ao trabalhador. ${ }^{2}$

\section{Referências}

ABRIC, J.C. A abordagem estrutural das representações sociais. In: MOREIRA, A.S.P.; OLIVEIRA, D. (Org.). Estudos interdisciplinares de representação social. Goiânia: AB, 1998. p. 27-38.

AUGUSTO, V.G. et al. Um olhar sobre as LER/DORT no contexto clínico do fisioterapeuta. Rev Bras Fisioter. , v. 12, n. 1, p. 49-56, 2008.

BAHIA, L.; SCHEFFER, M. Planos e Seguro de Saúde. 1a ed. Marília: Unesp, 2010.

BARDIN, L. Análise de conteúdo. Lisboa: Ediçôes 70, 1977.

BRASIL. Ministério da Saúde e Ministério da Previdência Social. Resoluçóes da $3^{a}$ Conferência Nacional de Saúde do Trabalhador. Brasília: Ministério da Saúde e Previdência Social; 2006. Disponível em: <http://www.anamt.org.br/downloads/realtorio_final_CNST_24_03_06. pdf >. Acesso em: 07 jan 2009.

CAETANO, V.C.; CRUZ, D.T.; LEITE, I.C.G. Fisioterapia na saúde do trabalhador: um campo de análise da representação social. Cad. Saúde Coletiva. Rio de Janeiro, v. 17, n. 2, p. 453-64, 2009.

CHAMMÉ, S.J. Saúde e organização social. Marília: Unesp, 1988.

GOMES, R.; MENDONÇA, E.A.; PONTES, M.L. As representaçóes sociais e a experiência da doença. Cad. Saúde Pública, v. 18, n. 5, p. 1207-14, 2002.

HERZLICH, C. La représentation sociale. In: MOSCOVICI S. (Org.). Introduction à la psychologie sociale. Paris: Larousse, 1972.

HOEFEL, M.G. et al. Uma proposta em saúde do trabalhador com portadores de LER/ DORT: grupos de ação solidária. Cad. psicol. soc. trab., v. 7, p. 31-9, 2004.

JODELET, D. As representações sociais: um domínio em expansão. In: (Org.). As representaçôes sociais. Rio de Janeiro: EdUERJ, 2001. 
LACAZ, F.A.C. O campo Saúde do Trabalhador: resgatando conhecimentos e práticas sobre as relações trabalho-saúde. Cad. Saúde Pública. Rio de Janeiro, v. 23, n. 4, p. 757-66, 2007.

LAPLANTINE, F. Antropologia da doença. In: (Org.). Parte I Questôes de método; Parte II As formas elementares da doença. 1a ed. São Paulo: Martins Fontes, 1991. p. 10-19. LEFF, E. Epistemologia ambiental. São Paulo: Cortez, 2001.

MINAYO, G.C.; THEDIM, C.S.M. A construção do campo de saúde do trabalhador: percursos e dilemas. Cad. Saúde Pública. Rio de Janeiro, v. 13, n. 2, p. 21-32, 1997.

MINAYO, M.C.S. O desafio do conhecimento: pesquisa qualitativa em saúde. $8^{\mathrm{a}}$ ed. São Paulo: Hucitec, 2004.

MOSCOVICI, S. A representação social da psicanálise. Rio de Janeiro: Zahar, 1978.

NEVES, R.F.; NUNES, M.O. Da legitimação a (re) significação: o itinerário terapêutico de trabalhadores com LER/DORT. Ciênc. saúde coletiva. Rio de Janeiro, v. 15, n. 1, p. 211-20, 2010.

ROCHA, A.M.; FELLI, V.E.A. A saúde do trabalhador de enfermagem sob a ótica da gerencia. Rev Bras Enferm., v. 57, n. 4, p. 453-58, 2004.

SATO, L. Prevenção de agravos à saúde do trabalhador: replanejando o trabalho através das negociações cotidianas. Cad. Saúde Pública. Rio de Janeiro, v. 18, n. 5, p. 1.147-66, 2002.

SILVA, F.C.M. et al. Representação social e reabilitação: consideraçōes conceituais. In: CONGRESSO BRASILEIRO DE TERAPIA OCUPACIONAL., 10. Contextos, territórios e diversidades. Anais... Goiânia (GO), 2007.

TURATO, E.R. Tratado da metodologia da pesquisa clínico-qualitativa: construção teóricoepistemiológica, discussão comparada e aplicação nas áreas da saúde e humanas. 2a ed. Petrópolis: Vozes, 2003.

WAGNER, W. Representações sociais: gênese, estrutura e relações. In: MOREIRA, A.S.P.; OLIVEIRA, D. (Org.). Estudos interdisciplinares de representação social. Goiânia: $\mathrm{AB}, 1998$. p. 3-25.

WALSH, I.A.P. et al. Capacidade para o trabalho em indivíduos com lesões músculoesqueléticas crônicas. Rev. Saúde Públ. São Paulo, v. 38, n. 2, p. 149-56,2004.

WÜNSCH FILHO, V. Perfil epidemiológico dos trabalhadores. Rev. Bras. Med. Trab., v. 2, n. 2, p. 103-17, 2004.

\section{Nota}

${ }^{1}$ O CEREST caracteriza-se por atender trabalhadores com DORT e/ou que sofreram algum tipo de acidente de trabalho. Realiza, dentro de uma trajetória de intervençôes, orientações e um programa especial de atendimento para esses trabalhadores, composta por assistente social, médicos, psicólogos e fisioterapeutas.

${ }^{2}$ V.C. Caetano planejou o estudo, realizou a coleta e análise dos dados e foi o redator principal do artigo; I.C.G. Leite e G.A. Silva colaboraram no planejamento do estudo, na análise dos dados e na redação do artigo. D.T. Cruz e S.M. Carvalho contribuíram na confecção do artigo. 
Health-disease process: a study of social representations of workers with WMSDSs

This paper was based on a study that examined the social representations of health-illness process among workers with work-related musculoskeletal disorders (WMSDs), users of the Reference Center of Occupational Health (CEREST) in the city of Juiz de Fora, state of Minas Gerais. Information was collected through semistructured interviews with 12 workers, aged between 29 and 55 years. Data were subjected to thematic analysis. The themes of analysis called "representation of health" and "representation of illness" set that, for these workers, illnesses and labor disability represent a painful gap and the destruction of life projects. Tables of deterioration of living conditions and work degradation, reflected on the health of workers, refer us to sustain that the prevention of health problems that would find a higher degree of resolution would be the replanning of work process' organization and effective performance of public health policies, through symbolic representations of broader health, illness and healing.

> Key words: health; disease; workers; WMSDs; social representation. 